\title{
La justificación funcional del pacto comisorio en la compraventa
}

\author{
Claudia Mejías Alonzo* \\ Gonzalo Severin Fuster**
}

\begin{abstract}
RESUMEN
En este trabajo se analiza críticamente el pacto comisorio (arts. 1877 y ss. CC), con el fin de determinar cuál es su función y utilidad. En relación con el pacto comisorio simple, se analizan dos cuestiones: la justificación de su regulación legal y la justificación de su inclusión en un caso concreto. En relación con el pacto comisorio calificado, se analiza cuál es el alcance que puede atribuirse a la expresión ipso facto. El trabajo se desarrolla sobre la premisa que una correcta lectura acerca de la función de este pacto exige considerar no solo su regulación, sino también la forma en la que en la actualidad se entiende que opera la facultad resolutoria exart. 1489 CC.
\end{abstract}

Incumplimiento contractual - compraventa - resolución - pacto comisorio

\section{The function of the termination clause for buyer's breach of contract}

\begin{abstract}
According to the Chilean Civil Code (arts. 1877 ys.), the parties of a sale contract are allowed to introduce a termination clause in case of breach by the buyer (the roman lex commisoria). This agreement typically gives the seller the right to terminate the contract "simple termination clause"). However, the parties could also agree that contrat will be terminate "ipso facto" in case of breach ("qualified termination clause"). This article explores the function of those clauses, within the context of a legal system where it is recognised the seller's right to termination, in case of breach, as a default rule (art. 1489 CC).
\end{abstract}

Breach of contract - sales - termination - lex comissoria

* Doctora en Derecho, Pontificia Universidad Católica de Valparaíso. Profesora de Derecho civil, Pontificia Universidad Católica de Valparaíso. Correo electrónico: claudia.mejias@pucv.cl

** Doctor en Derecho, Universidad Autónoma de Madrid. Profesor de Derecho civil, Pontificia Universidad Católica de Valparaíso. Correo electrónico: gonzalo.severin@pucv.cl

Este trabajo se inserta en el Proyecto de Investigación DER2014-53972, financiado por el Ministerio de Economía y Competitividad de España.

Artículo recibido el 5.4.2016 y aceptado para su publicación el 10.7.2017. 


\section{INTRODUCCIÓN ${ }^{\mathrm{I}}$}

$\mathrm{N}$

uestro Código Civil regula el pacto comisorio en el Libro IV, Título XXIII (De la compraventa), párrafo 10 (Del pacto comisorio). Según dispone el art. 1877 inc. 1 CC, (p)or el pacto comisorio se estipula expresamente que, no pagándose el precio al tiempo convenido, se resolverá el contrato de venta. El supuesto al que se refiere el denominado pacto comisorio es el incumplimiento de una de las obligaciones derivadas del contrato: la obligación del comprador de pagar el precio. Tal pacto, según anuncia el propio art. 1877 CC, produce los efectos que se expresan en los arts. 1878 a 1880 CC.

El objeto de estudio de este trabajo es el pacto comisorio al que se refieren los arts. 1877 a 1880 CC, que llamaremos, como algunos autores lo hacen, "típico"2, con el fin de determinar cuál es su función y su utilidad ${ }^{3}$. En primer lugar, analizaremos el llamado pacto comisorio "simple", del que se tratan dos cuestiones. Por un lado, se aborda la justificación de su regulación en el Código Civil, habida cuenta del reconocimiento, en el art. 1489, de una facultad resolutoria en caso de incumplimiento (la justificación "sistémica"), poniendo en discusión la idea generalizada de que el pacto comisorio simple no es más que la facultad resolutoria expresada a partir de un estudio histórico que da cuenta de las diferentes fuentes de esas dos instituciones. Y por otro lado, se aborda la justificación de su inserción en un contrato de compraventa en particular (su justificación "práctica”). En segundo lugar, analizaremos el denominado pacto comisorio "calificado", en relación con el cual interesa, específicamente, determinar el alcance que puede atribuirse a la expresión ipso facto. En nuestra opinión, una correcta lectura acerca de la función que puede atribuirse al pacto comisorio -tanto del "simple" como del "calificado"- exige considerar no solo la regulación legal de esta figura, sino también la forma en la que se entiende funciona el sistema general de resolución por incumplimiento contractual exart. 1489 CC.

\footnotetext{
${ }^{1}$ Abreviaturas utilizadas: art.(s) = artículo(s); CC = Código Civil chileno; $\mathrm{CPC}=$ Código de Procedimiento civil; cdo. $=$ considerando; Code $=$ Código Civil francés; $\mathrm{SCA}=$ Sentencia de Corte de Apelaciones; SCS = Sentencia de Corte Suprema.

${ }^{2}$ Vial del Río, V., Manual de las Obligaciones en el Código Civil chileno, $2^{\mathrm{a}}$ ed., Editorial Biblioteca Americana, Santiago, 2007, p. 77.

${ }^{3}$ Es indispensable, antes de continuar, realizar dos precisiones terminológicas. La primera es que el pacto que establece que se resolverá el contrato por incumplimiento de la obligación de entregar la cosa, y cualquier otro pacto de resolución que tenga como supuesto el incumplimiento de otras obligaciones, derivadas del contrato de compraventa o de otros contratos, no pueden, en puridad, ser calificados de "pactos comisorios", si bien son pactos perfectamente posibles. Pese a ello, la denominación de "comisorios" a esos pactos es bastante común en la doctrina. La segunda precisión es que se denomina, también, "pacto comisorio" al que faculta al acreedor para apropiarse de las cosas que le fueron entregadas en garantía, en caso de que el deudor incumpla la obligación garantizada (históricamente, y todavía hoy en Derecho comparado; sobre ello, véase, por ejemplo, Wegmann Stockebrand, A., "Algunas consideraciones sobre la prohibición del pacto comisorio y el pacto marciano”, Revista chilena de Derecho privado, v. 13, 2009, pp. 95-122).
} 


\section{LA JUSTIFICACIÓN DEL PACTO COMISORIO SIMPLE}

El pacto comisorio se llama doctrinalmente "simple" por contraposición al que se denomina "calificado", que es el que contiene la cláusula de resolución ipso facto (art. 1879 CC). Considerando lo dicho, puede definirse el pacto comisorio "simple" al tenor del art. 1877 CC, añadiendo que no lleva dicha cláusula.

En doctrina, suele afirmarse que el pacto comisorio simple "se reduce a convertir en condición resolutoria expresa y pactada por los contratantes, la condición resolutoria tácita a la que se refiere el art. 1489" ${ }^{4}$. Nuestros tribunales suelen reproducir esa misma afirmación ${ }^{5}$. En consecuencia, se dice que "la resolución en el pacto comisorio simple opera en la misma forma que en la condición resolutoria tácita [, siendo] necesario, pues, que una sentencia declare resuelto el contrato" 6 ; que "sus efectos [...] son los mismos de la condición resolutoria tácita" ${ }^{7}$ y que, al incorporar un pacto comisorio simple, "las

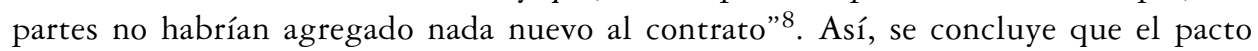
comisorio simple "[e]s más inútil que beneficioso" ") es más, se dice derechamente que es una estipulación "ociosa" 10 , que "bien podría suprimirse" ${ }^{11}$; y que "carece de interés práctico y dogmático"12.

Si se entiende, como lo hace la mayoría de nuestra doctrina, que el pacto comisorio simple solo expresa aquello que el art. 1489 CC tácitamente entiende incorporado a todo contrato bilateral, parece lógico concluir que tal pacto es innecesario e inútil. Y más aún si se considera el texto del art. $1873 \mathrm{CC}$-al que se remite el art. $1878 \mathrm{CC}-$, que otorga un derecho al vendedor, en caso de que el comprador no pague el precio, para exigir el

${ }^{4}$ Claro Solar, L., Explicaciones de Derecho civil chileno y comparado, T. 10: De las obligaciones, Jurídica de Chile, Santiago, 1988 (v. 5, reimpresión), p. 202; y en el mismo sentido, por ejemplo, Abeliuk Manasevich, R., Las obligaciones. Tomo I, 6a ed., LegalPublishing (Thompson Reuters), Santiago, 2014, p. 661; Larraín Ríos, H., Teoría General de las Obligaciones, LexisNexis, Santiago, 2003, pp. 99-100; Peñailillo Arévalo, D., Obligaciones. Teoría general y clasificaciones. La resolución por incumplimiento, Jurídica de Chile, Santiago, 2006, p. 419; Ramos Pazos, R., Manual de Derecho civil. De las obligaciones, 10ª ed., Jurídica de Chile, Santiago, 2007 , p. 45.

${ }^{5}$ Así, por ejemplo: (el pacto comisorio simple) no es más que la cláusula resolutoria tácita, pero expresada en un contrato, produciéndose los mismos efectos en uno y otro [SCA de Antofagasta, de 20 de junio de 2011 (215-2011), Contratista Juan Fuentes Castillo E.I.R.L. con Corporación Municipal de Desarrollo Regional de Antofagasta, cdo. 2 (CL/JUR/10179/2011)].

${ }^{6}$ Alessandri, A.; Somarriva, M., Vodanovic, A., Tratado de las obligaciones. Volumen de las obligaciones en general y sus diversas clases, $2^{a}$ ed., Jurídica de Chile, Santiago, 2001, p. 279. En el mismo sentido, Abeliuk, cit. (n. 4), p. 663.

${ }^{7}$ Ramos Pazos, cit. (n. 4), p. 45. En el mismo sentido, Claro Solar, cit. (n. 4), p. 205.

${ }^{8}$ Claro Solar, cit. (n. 4), p. 202.

${ }^{9}$ Alessandri Rodríguez, A., De la compraventa y de la promesa de venta, Jurídica de Chile, Santiago, 2003 , T. II. V. 1, p. 459.

${ }^{10}$ Ramos Pazos, cit. (n. 4), p. 45.

11 Alessandri Rodríguez, cit. (n. 9), p. 511.

${ }^{12}$ Pizarro Wilson, C., Las cláusulas resolutorias en el Derecho civil chileno, en De la Maza, I. (edit.) Cuadernos de Análisis jurídico. Colección Derecho Privado III. Temas de contratos., Universidad Diego Portales, Santiago, 2006, p. 246. 
precio o la resolución de la venta, sin necesidad de que así se haya pactado (cuestión que, por lo demás, se desprende también del propio art. 1877 inc. 2 CC). Tal conclusión, sin embargo, merece ser analizada con mayor detenimiento. Como se ha anunciado, dos son las cuestiones que nos interesa abordar aquí. Una primera cuestión tiene que ver con la justificación de la consagración y regulación del pacto comisorio simple en el sistema del Código Civil. Una segunda cuestión es, si la regulación específica del pacto comisorio simple (arts. 1877, 1878 y 1880 CC) podría justificar su introducción en un contrato de compraventa, lo que implica preguntarse si es efectivo que, como suele afirmarse, este pacto no es sino la condición resolutoria tácita expresada, y que sus efectos son idénticos.

\section{Primera cuestión. Justificación de la regulación del pacto comisorio simple en el sistema del Código Civil}

En nuestra opinión, la regulación específica del pacto comisorio, al interior de la regulación de la compraventa, es un vestigio histórico, que carece de justificación dentro del sistema de resolución por incumplimiento adoptado por el Código Civil. Es, por así decirlo, resultado de una deficiente técnica legislativa. Andrés Bello hace convivir reglas específicas o casuísticas, de raigambre romana (arts. 1877 y ss. CC), con reglas de aplicación más o menos general (arts. 1873 y 1489 CC), concebidas con posterioridad, y que solo en parte se pueden considerar el resultado de un proceso de generalización o abstracción de esas reglas específicas. Esta hipótesis se confirma, como veremos a continuación, si se consideran las distintas fuentes que Andrés Bello tuvo a la vista a la hora de regular, por un lado, el pacto comisorio por no pago del precio en la compraventa (arts. 1877 a 1880 del CC) y, por otro lado, la llamada "condición resolutoria tácita" (art. $1489 \mathrm{CC})^{13}$.

\section{i. Las fuentes de la regulación del pacto comisorio}

Tratándose de la regulación del pacto comisorio, contenida en los artículos 1877 a 1880 del Código Civil, nuestra doctrina tradicional suele reconocer la influencia de R. J. Pothier (1699-1772) ${ }^{14}$. En nuestra opinión, ello puede admitirse, pero limitadamente: solo en cuanto se le considere una fuente inmediata y una entre varias otras, y, en todo caso, solo en relación con una parte de la mentada regulación legal, específicamente, en relación con dos aspectos. El primer aspecto es la definición del pacto comisorio

${ }^{13}$ En relación con este punto, conviene tener presente que en el libro De los contratos y de las obligaciones convencionales del Proyecto de Código Civil de 1847 (en adelante, PCC 1847), no se regula el pacto comisorio, y tampoco la condición resolutoria con carácter general; aunque sí se incluyen dos disposiciones cuyo contenido corresponde al de los artículos 1826 y 1873 CC (arts. 24 y 46 PCC 1847, respectivamente). La condición resolutoria tácita y el pacto comisorio son incluidos en el Proyecto de Código Civil de 1853 (en adelante, PCC 1853), en el artículo 1665, y arts. 2055 a 2059, respectivamente.

${ }^{14}$ Por todos, Claro Solar, cit. (n. 4), p. 201. 
contenida en el art. 1877 inc. $1 \mathrm{CC}^{15}$. El segundo aspecto es la idea de que el vendedor puede siempre elegir entre exigir el precio y la resolución de la venta -art. 1878 CC en relación con el art. 1873 CC-, y puede admitirse la influencia de Pothier aun cuando el propio Bello cita como fuente a "Delvincourt" ${ }^{16}$. Sin embargo, como se ha anunciado, esa posible influencia de Pothier no puede, en ningún caso, considerarse decisiva: esos dos aspectos aparecen también formulados, y de manera similar, en otra importante fuente del Código Civil chileno: Las Partidas (P. 5, 5, 38) ${ }^{17}$. Desde luego, no han de sorprender la similitud entre las ideas expuestas por Pothier y las que se encuentran en la base de la regulación de Las Partidas, porque ambas beben de una fuente común: la lex commisoria del Derecho romano ${ }^{18}$.

${ }^{15}$ Para Pothier, "Le pacte commissoire est une clause ou convention qui s'insère quelquefois dans les contrats de vente, par laquelle les parties conviennent que, si l'acheteur ne paie pas le prix dans un certain temps limité, le contrat será résolu" [Pothier, R. J., Traité du contrat de vente, n. 459, en el título que trata $D e$ la résolution du contrat de vente, en vertu du pacte commissoire (Ouvres de R.-J. Pothier, contenant les traités du droit français. T. 1, H. Tarlier, Bruxelles, 1831, p. 392)]. No obstante, la redacción del art. 1877 inc. 1 CC se asemeja más a la definición que ofrece Delvincourt: "Le pacte commisoire est celui par lequel le vendeur stipule que, faute par l'acquéreur d'avoir payé le prix au terme convenu, la vente será résolue" [Delvincourt, C.E., Cours de Code civil, $9^{a}$ ed., P.J. de Mat, Bruxelles, 1925, t. 5, p. 145]. En nuestra opinión, es probable que esta haya sido la fuente inmediata del art. $1877 \mathrm{CC}$, pues, como señala el propio Bello, en el Proyecto de 1853 (PCC 1853) son frecuentes las citas a Delvincourt [Bello, A., Código Civil (1853) (Proyecto de), en Consejo de instrucción pública, Obras completas de don Andrés Bello, V. XII: Proyecto de Código Civil de 1853, Imprenta de Pedro Ramírez, Santiago, 1888, p. 3], y si bien es cierto que no existe cita a dicho autor a propósito del art. 2056 PCC 1853 (actual art. 1877 CC), sí la hay a propósito del art. 2057 PCC 1853 (actual art. $1878 \mathrm{CC}$ ), como se explica en la nota siguiente.

${ }^{16}$ Delvincourt, al tratar el pacto comisorio (art. 1656 Code; véase infra nota 22) destaca que nunca implica una resolución de pleno derecho, pero no expresa con claridad la idea de que el vendedor tiene derecho a optar entre el cumplimiento y la resolución, pues pone el acento en el derecho del comprador a pagar, más que en el derecho del vendedor a exigir el pago [cfr. Delvincourt, cit. (n. 15) t. 7, pp. 153-154]. Esa idea aparece expuesta, sin embargo, en el estudio de la condición resolutoria tácita [Delvincourt, C.E., Cours de Code civil, cit. (n. 15) t. 5, p. 148]. En cambio, la idea de que la resolución derivada de un pacto comisorio, aun cuando se haya pactado que opere de pleno derecho, no priva al vendedor del derecho a demandar el cumplimiento, y que él puede elegir no utilizar el pacto, sí aparece expresada con claridad por Pothier: "Le pacte commissoire este censé ne se faire qu'en faveur du vendeur, et il n'acquiert de droit qu'à lui (...) le vendeur peut ne pas user de ce pacte, et, au lieu de demander la résolution du contrat, poursuivre l'acheteur pour le paiment, sans que l'achetuer puisse etre admis á la demander" [Pothier, Traité du contrat de vente, n. 459, cit. (n. 15), p. 392].

${ }^{17}$ A propósito de las posturas ó pleitos que facen el vendedor y el comprador entre sí son valederas (ambas voces, "posturas" y "pleitos", significan, según el Diccionario de la RAE, "pacto" o "convenio"). La primera parte de P. 5,5,38 ofrece una definición: Si el vendedor et el comprador ponen pleito entre sí, quel comprador pague el prescio á dia señalado, et si non lo pagare aquel dia sea desecha por ende la véndida, que atal pleito como este es valedero (...); y luego, se reconoce esta idea de que el vendedor puede elegir entre el cumplimiento y la resolución: $(p)$ ero con todo eso en su escogencia es del vendedor de demandar todo el prescio, et facer que vala la véndida ó de revocarla (...).

${ }^{18}$ Recordemos que, en el Derecho romano, no existía una acción general para solicitar la resolución del contrato, y solo se contó con algunas reglas especiales y excepcionales que la establecieron, una de ellas fue la lex commissoria, en este sentido, véase, por ejemplo: Arangio-Ruiz, V., La compravendita in diritto romano, t. II. Jovene, Napoles, 1954, pp. 223-227 y 402-403, Boyer, G., Recherches historiques sur la résoltuion des contrats, Les presses universitaires de France, Paris, 1924, p. 105 y ss.; Cassin, R. De l'exception tirée de l'inexécution dans les rapports synallagmatiques: exception non adimpleti contractus, Paris, Librairie de la Société du Recueil 
Ahora bien, en nuestra opinión, la influencia de Pothier sí podría considerarse decisiva en relación con un particular aspecto de la regulación del pacto comisorio en el Código Civil chileno: la afirmación de que esa estipulación es un elemento de la naturaleza del contrato de compraventa (art. 1878 inc. 2 CC). En efecto, el carácter implícito que se le reconoce al pacto comisorio en la compraventa no encuentra su origen en el Derecho romano, y no se puede considerar herencia del Derecho español, que en este punto no innovó respecto de aquel ${ }^{19}$. Tampoco es posible reconocer influencia del Code, que no contiene ninguna norma similar a los arts. 1877 inc. 2 y 1873 CC $^{20}$. La comprensión de la lex commissoria como un pacto implícito en la compraventa parece tener su origen en la doctrina francesa, entre los siglos XVI y XVII. En Domat es posible hallar esa idea. Este autor, al tratar de los compromisos u obligaciones que asume el comprador frente al vendedor, expone, que si el comprador no ha pagado el precio, el vendedor podrá, si todavía no se ha entregado la cosa, retenerla en garantía, y, en el caso que ya se hubiera entregado la cosa vendida, demandar la resolución de la venta, cuestión que Domat afirma sin referencia alguna a la necesidad de que exista un pacto expreso en

Sirey, 1914, pp. 94-95; Guzmán Brito, Derecho privado romano, T. II, Jurídica de Chile, Santiago, 2010, p. 144; Jörs, P.; Kunkel, W., Derecho privado romano, trad. de Prieto Castro, L, Editorial Labor, Barcelona, 1937, pp. 300-301; y Zimmerman, R., The Law of Obligations. Roman foundations of the civilian tradition, $1^{\mathrm{a}}$ ed, Juta and Co., Cape Town, 1990 (reimpresión 1992), p. 738.

Para el derecho romano se trataba de un pacto especial, incorporado expresamente en la compraventa, en cuya virtud el vendedor se reservaba la facultad de tener por no comprada la cosa si el comprador no pagaba el precio dentro de cierto plazo, con la finalidad de recuperar la cosa o no entregarla $[\mathrm{D} .18,3(\mathrm{De}$ lege commisoria); y C. 4, 54: De pactis inter emptorem et venditorem compositis]. Y esa resolución, por tanto, no operaba ipso iure por el solo hecho del incumplimiento; el vendedor podía utilizar, o no, el pacto, quedando en consecuencia a su arbitrio resolver el contrato o exigir el pago del precio por medio de la actio venditi. En las fuentes es claro que el pacto está establecido en beneficio del vendedor, y no del comprador. Acerca del punto, por ejemplo, D. 18, 3, 2: Cuando el vendedor de un fundo se bubiere expresado de este modo en un pacto: si no se hubiera pagado el precio hasta tal día, quede como no comprado el fundo, se considera que se tiene como no comprado el fundo, en este caso, si el vendedor quisiera que quedase como no comprado, porque esto se habría expresado por causa del vendedor; porque si de otro modo se entendiera, quemada una casa de campo, estarla en el arbitrio del comprador, no dando el precio, hacer que quedase sin comprar el fundo, que bubiese estado á su riesgo (destacado añadido). D. 18, 3, 3: Porque el pacto de la ley comisoria, que se añade en las ventas, lo utilizará el vendedor, si quisiera, no también contra su voluntad [trad. de García del Corral, I., Cuerpo de Derecho Civil Romano, Jaime Molinas, Barcelona, 1889].

${ }^{19}$ Con relación al derecho romano véase la nota anterior. Recogida la lex commissoria en Las Partidas (P. $5,5,38)$, conservó, con los siglos, su característica de ser un pacto expreso, y nunca se llegó a considerar un elemento de la naturaleza en las compraventas; y así se explica este pacto por la doctrina española del siglo XIX, anterior a la codificación civil (véase, por ejemplo, Gómez de la Serna, P; Montalban, J. M., Elementos del derecho civil y penal de España, t. 2, Establecimiento Tipográfico Calle del Sordo, Madrid, 1842, pp. 63 y 64). El Proyecto de Código Civil español de Goyena, de 1951, rompía con esa tradición, pues no recogía la regulación contenida en Las Partidas, y, en cambio, solo contemplaba un supuesto particular de resolución por no pago del precio, limitada a la venta de bienes inmuebles (art. 1433), reproduciendo, sin más, la regulación del Código francés respecto de la materia (véase la nota siguiente). El art. 1504 del Código Civil español de 1889 conservó esa misma regla.

${ }^{20}$ A diferencia de lo que ocurre en nuestro Código Civil, el Code no regula el pacto comisorio en un párrafo especial dentro de la regulación compraventa, sino que solo considera una regla especial, el art. 1656, que, podría decirse, es similar a nuestro artículo 1879 CC, aunque solo está referida a bienes inmuebles. 
tal sentido ${ }^{21}$. Pero en Pothier hallamos esa idea expresada de una forma más amplia y explícita: más amplia, pues la resolución no aparece vinculada al hecho de que se haya entregado la cosa vendida; y explícita, porque señala expresamente que el vendedor tiene ese derecho a resolver "aun cuando no haya pacto comisorio" 22 ; que es precisamente lo que consagra el art. 1877 inc. 2 CC.

\section{ii. Las fuentes de la regulación de la llamada "condición resolutoria tácita"}

Nuestra doctrina identifica como fuente del artículo 1489 CC, el art. 1184 Code d $^{23}$. Ahora bien, hay que tener presente que, pese a que existe cierta similitud entre esos dos artículos, su tenor no es idéntico. El art. 1184 Code contiene varias reglas que nuestro Código no recoge: i) se dice explícitamente que la resolución no opera de pleno derecho; ii) se dice explícitamente que ella debe demandarse ante los tribunales; y iii) se señala que el juez puede, según las circunstancias, fijar un plazo al deudor para que cumpla la obligación $^{24}$. La influencia del art. 1184 Code en la redacción del art. 1489 CC es, por decirlo así, limitada ${ }^{25}$.

Pues bien, más allá de esas diferencias, ambos artículos reconocen a las partes de un contrato bilateral, un derecho a pedir la resolución del contrato en caso de incumplimiento, y, en ambos -y esto es lo que nos interesa destacar-, ello se explica como

${ }^{21}$ L. I, T. II, S. 3, párrafos 3 y 5, respectivamente (Domat, Les lois civiles dans leur ordre natural, París, la Veuve Cavelier, 1771, p. 31). Domat, más adelante, en ese mismo libro, se refiere especialmente a las condiciones y pactos de la compraventa, y entre ellos, menciona el pacto o cláusula resolutoria por no pago del precio, admitiendo que tal pacto puede también recaer sobre otras obligaciones de las partes en la compraventa: Si l'acheteur ne paye au terme aprés la délivrance, le vendeur pourra demander la resolution de la vente, faute de payement (L. I, T, II, S. 3, ley 8, ibid., p. 128). Y agrega a continuación: Et elle sera ordonnée, ou d'abord, s'il y avoit du péril que le vendeur perdît la chose et le prix: ou, si ce péril cesse, aprés un délay selon les circonstances. Et ce délay n'est pas refusé, quand même il seroit dit par le contract, que la vente seroit résolue par le défaut de payement au terme. (...). Si l'acheteur ne paye au terme aprés la délivrance, le vendeur pourra demander la resolution de la vente, faute de payement.

${ }^{22}$ (L)'on admet un vendeur à demander la résolution du contrat de vente pour cause de défaut de paiment du prix, quoiqu'il n'y ait pas de pacte commissoire [Pothier, Traité du contrat de vente, n. 476; cit. (n. 15), p. 395].

23 "El artículo 1184 francés [...] ha servido de modelo a nuestro artículo 1489" [Claro Solar, L., "Ligeras observaciones sobre la condición resolutoria y el pacto comisorio (notas para alegar)", en Tavolari Oliveros, R., Doctrinas esenciales. Derecho civil. Contratos. Tomo 1, Santiago, Jurídica de Chile, 2010, p. 753; publicado originalmente en Revista de Derecho y Jurisprudencia, T. VIII, N. 7, 1911]. En este mismo sentido, Alessandri, A., Derecho civil. Primera parte. Teoría de las obligaciones, Impr. Cisneros-San Francisco, Santiago, 1930, p. 180.

${ }^{24}$ Art. 1184 Code: La condition résolutoire est toujours sous-entendue dans les contrats synaliagmatiques pour le cas où l'une des deux parties ne satisfera point à son engagement. / Dans ce cas, le contrat n'est point résolu de plein droit./ La partie envers laquelle l'engagementn'a point été exécuté, a le choix ou de forcer l'autre à l'exécution de la convention lorsqu'elle est possible, ou d'en demander la résolution avec dommages et intérêts./ La résolution doit être demandée en justice et il peut être accordé au défendeur un délai selon les circonstances.

${ }^{25}$ Resulta interesante destacar que, en esta materia, la influencia que, en otros Códigos decimonónicos, tuvo la regulación de la condición resolutoria tácita del Code, fue más acusada. En efecto, reprodujeron el tenor del mentado art. 1184 Code, casi sin modificaciones, el Código holandés de 1938; el italiano de 1865, y, también el español de 1889, siguiendo al Proyecto de García Goyena de 1951 (proyecto que, por lo mismo, puede descartarse como fuente de nuestro 1489 CC). 
una condición subentendida o implícita. De hecho, en ambos códigos la regla se sitúa dentro del párrafo dedicado a las obligaciones condicionales. ¿Cuál es el origen de esa aproximación del art. 1184 Code, que fue adoptada también por nuestro Código Civil? En los discursos y exposiciones de motivos del Code, no hay referencia alguna a este punto ${ }^{26}$. Si uno atiende a la redacción del art. 1184 Code, se observa con claridad la influencia de las ideas de Pothier, así como están expuestas en su Traité des obligations ${ }^{27}$. Sin embargo, ello no quiere decir que Pothier haya "inventado" la idea de que el incumplimiento del contrato opera como una especie de condición resolutoria implícita. Dicha forma de ver las cosas estaba presente en los autores franceses, ya a partir del siglo XVI, como resultado de la práctica contractual y de ciertas aportaciones del Derecho canónico ${ }^{28}$.

\section{Segunda cuestión. Justificación práctica de la introducción de un pacto comisorio simple en un contrato de compraventa}

Más allá de la justificación sistémica de la regulación, podemos preguntarnos acerca de la utilidad de introducir un pacto comisorio simple en un contrato de compraventa, atendida la normativa vigente. $\mathrm{O}$ sea, ¿es útil expresar aquello que se entenderá igualmente incorporado de forma tácita? Dicho en esos términos, la respuesta parece lógica: la introducción del pacto comisorio simple es inútil en la compraventa. Y esa es, como ya se ha dicho, la respuesta común. Por nuestra parte, creemos que esa respuesta no es correcta. La inclusión de un pacto comisorio implicará en todo caso una disminución del tiempo

${ }^{26} \mathrm{Si}$ se analizan esos antecedentes [vid. Code Civil Francais. Discours et exposé des motifs, Huyghe, Bruxelles, 1804], no se encuentra, entre quienes se refieren a la regulación de las obligaciones condicionales, y en particular, a la condición resolutoria tácita, referencia a la doctrina de Pothier, y de hecho, no hay explicación alguna sobre el origen dogmático de esa regla [en efecto, no la hay ni en la exposición de Bigot-Préameneu, orador del ejecutivo (t. 3, p. 140), ni en la exposición de Mouricault, orador del Tribunal (t. 3, p. 247)].

${ }^{27}$ En efecto, Pothier señala con claridad que esa resolución puede operar aunque no se haya pactado, que ella no opera de pleno derecho y que debe demandarse en tribunales, y, explica que, en la práctica francesa, se entiende que el juez puede otorgar un plazo al deudor demandado para que cumpla [Pothier, Traité des obligations, n. 673; cit. (n. 15), p. 210].

${ }^{28}$ Conviene destacar que, en el Derecho canónico, la resolución aparece vinculada a la figura de los juramentos, concebida como una sanción en contra del promitente que no guardaba fe de la promesa realizada (Frangenti fidem non est fides servanda o Non servanti fidem, fides non servantur eidem o Frangenti fidem fides frangatur eidem) [acerca del punto, véase, por ejemplo, Boyer, cit. (n. 18), p. 240 y ss.; Capitant, H., De la causa de las obligaciones, Editorial Góngora, Madrid, 1930, pp. 322-323. Cassin, cit. (n. 18), pp. 4246.; y Levy, J. Ph.; Castaldo, A., Histoire du droit civil, Paris, Dalloz, 2002, n. 573, p. 833]. En tiempos de Inocencio III (1198-1216), ese extenso “ámbito” de aplicación -toda infracción de una obligación jurídica o de las reglas de la moral cristiana- se limita, acentuando su carácter contractual, y configurándose la idea de que el nacimiento de una obligación contractual tiene como condición necesaria y suficiente la voluntad de obligarse del deudor; y se presumió que en todo juramento el deudor subordinaba sus compromisos a la realización de ciertas condiciones sobreentendidas. Se admitió que era razonable entender que todo contratante se obligaba con la finalidad de obtener las ventajas que le fueron prometidas, y que si ello no ocurría, la promesa perdía fuerza obligatoria. En principio, ello solo retardaba el cumplimiento de la obligación correlativa, pero, si el incumplimiento era definitivo, conllevaba a la resolución del contrato [por todos, Boyer, cit (n. 18), p. 225 y ss.]. 
para poder pedir la resolución, comparado con el tiempo que el vendedor tendría de no existir ese pacto; como se dirá a continuación. Adicionalmente, podría plantearse la pregunta acerca de si su inclusión conlleva una modificación de la facultad resolutoria del artículo 1489 CC en relación con la determinación de su supuesto de procedencia, esto es, si importa una diferente calificación del incumplimiento resolutorio; y podría plantearse, también, que la incorporación del pacto implica una modificación en la forma en que opera la resolución y en sus efectos respecto de terceros, en virtud de lo dispuesto en los arts. 1490 y 1491 CC.

i. En relación con la prescripción de la acción para pedir la resolución

Como se ha anunciado, la incorporación de un pacto comisorio implicará, en todo caso, una disminución del tiempo para poder pedir la resolución, respecto del tiempo que el vendedor tendría de no existir ese pacto ${ }^{29}$. Esta afirmación descansa en las siguientes premisas: 1era. No se requiere un pacto expreso para que el vendedor tenga derecho a pedir la resolución en caso de no pago del precio, pues ese derecho se tiene sin necesidad de pacto. (arts. 1489 y 1873 CC); 2 da. Si se incluye una cláusula que establece expresamente que el contrato se resolverá en caso de incumplimiento, ella se califica por la ley de "pacto comisorio", y produce los efectos que expresan los artículos 1878 y siguientes del CC; 3era. La existencia de un pacto comisorio simple no priva al vendedor del derecho a exigir el precio, según lo dispone expresamente el art. 1878 CC; 4 ta. El tenor del art. 1880 CC; 5 ta. La acción para pedir la resolución que tiene el vendedor en virtud de lo dispuesto en los artículos 1489 y 1873 CC, prescribe, a falta de regla especial, en el plazo ordinario de prescripción extintiva, esto es, cinco años desde que el derecho se ha hecho exigible (o sea, desde que se ha incumplido la obligación) ${ }^{30}$.

Teniendo en consideración esas premisas, es evidente que la incorporación de un pacto comisorio, en un caso concreto, no puede considerarse inútil. El pacto comisorio implica la creación convencional de una regla jurídica - "regla pactada"-, cuya función es sustituir a la regla que opera por defecto - "regla implícita”-. Esas dos reglas son estructuralmente diferentes. Ambas tienen la misma hipótesis (el hecho del incumplimiento de la obligación de pagar el precio), pero la consecuencia jurídica es distinta. La diferencia no radica en la posibilidad de exigir la resolución, tampoco en los efectos que produce, sino en la duración de ese derecho a exigir la resolución. Si rige la regla implícita, ese plazo es de cinco años desde que es exigible la obligación. Si la regla aplicable es, en

${ }^{29}$ La doctrina nacional ha puesto de relieve que la única diferencia con la facultad resolutoria exart. 1489 está en el plazo de prescripción, por todos Alessandri Rodríguez, cit. (n. 9), p. 459; Vío Vásquez, E., Las obligaciones condicionales, Escuela de tipografía salesiana, Concepción, 1945, pp. 342- 343. Díez Duarte, R., La compraventa, $2^{\mathrm{a}}$ ed,. El Jurista, Santiago, 2009, p. 346. Abeliuk, cit. (n. 4), pp. 675-677.

${ }^{30}$ Con la sola vigencia del Código Civil el plazo de prescripción de las acciones ordinarias, entre las que habría que calificar a la acción resolutoria del art. 1489 CC, era de veinte años. Así, el efecto restrictivo del plazo podía ser más importante. Tras la reforma que introdujo la Ley N. 6.162 el año 1938, el plazo máximo de prescripción se redujo a 15 años, y luego con la Ley N. 16.952 pasó a 5 años. 
cambio, la regla pactada, el plazo será aquel que las propias partes hubieren acordado, con el límite máximo que establece la ley, de cuatro años contados desde la fecha del contrato. La utilidad del pacto es evidente: es la vía por la que puede modificarse, válidamente, el plazo legal de prescripción de la acción general de resolución del art. 1489 CC; modificación que, en un caso concreto, podría ser muy importante, pues las partes pueden perfectamente fijar un plazo de meses o de días ${ }^{31}$.

En la medida que, como se ha explicado, la "regla pactada" sustituye a la "regla implícita”, excluyendo su aplicación, no existe propiamente, en este caso, concurso de normas. Corolario de ello es que, una vez trascurrido el plazo de la regla pactada, el vendedor no puede demandar la resolución exart. 1489 CC. Esta conclusión nos parece evidente, pero conviene destacarla, porque en alguna ocasión la Corte Suprema ha resuelto justamente lo contrario: la prescripción que señala el artículo 1880 es únicamente para el pacto comisorio, no para la prescripción que nace de la condición resolutoria tácita del artículo 1489; y como el artículo 1878 dice que por el pacto comisorio no se priva al vendedor de la elección de acciones que le concede el artículo 1873, siempre le quedaría al vendedor la acción resolutoria derivada del artículo $1489^{32}$.

Es evidente que la posición que defendemos no favorece a los intereses del vendedor, que en el supuesto en análisis, es la parte no incumplidora. Es más, el vendedor que estipule un pacto comisorio se verá perjudicado. Pero, a nuestro juicio -y esto es algo que no parece haber sido puesto de relieve por la doctrina-, el hecho de que lo dispuesto en el art. 1880 CC implique una limitación de los derechos del vendedor no justifica, dogmáticamente, que su aplicación pueda eludirse. Pues, según lo que se ha dicho, si las partes han introducido un pacto comisorio simple, hay que admitir que han querido precisamente que se produzca ese efecto determinado por la ley, porque lo conocen (art. $8 \mathrm{CC}$ ). Y, además, porque el sentido en que una cláusula puede producir algún efecto deberá preferirse a aquel en que no sea capaz de producir efecto alguno (art. 1562 CC). El comprador puede haber sido mejor negociador, o bien puede que la cláusula haya sido admitida por el vendedor a cambio de otra cosa (un mayor precio, por ejemplo); como sea, el acuerdo libre de las partes ha de respetarse (art. 1545 CC) si está dentro de los márgenes legales. En la lógica del Derecho privado, no habría razón para inclinar, en este caso, la balanza en favor del vendedor. Por último, las consideraciones acerca de lo beneficioso u odioso de una disposición (en este caso, el art. 1880 CC) son ajenas a la interpretación de las reglas del Código Civil (art. 23 CC).

${ }^{31}$ Es importante tener presente que, en nuestro medio, se entiende que rige un principio de indisponibilidad de las reglas respecto de la prescripción, sobre la base de que se trataría de reglas de orden público. Sin embargo, se ha discutido la validez de cláusulas que modifican los plazos legales de prescripción, aceptándose dichas cláusulas, en general, si ellas tienen por finalidad abreviarlos. Entre otras cosas, ello se sostiene sobre la base de que la propia ley lo admite excepcionalmente, como ocurre en el caso del pacto comisorio (véase, por ejemplo, Domínguez Águila, R., La prescripción extintiva, Editorial Jurídica de Chile, Santiago, 2004, pp. 42-43).

${ }^{32}$ SCS, de 7 de julio 1993 (16923-1993), Fisco de Chile con Inversiones y Comercial Transegeo Ltda. (cdo. 14) $[\mathrm{CL} / \mathrm{JUR} / 716 / 1993]$. 
ii. Otras posibles -y discutibles- justificaciones prácticas del pacto comisorio simple

Nos resulta relevante precisar si el pacto comisorio simple puede o no tener otras justificaciones de índole práctica que incidan en su establecimiento. En concreto abordaremos dos cuestiones, una vinculada a la procedencia del remedio resolutorio y otra, vinculada a los efectos que produce.

La primera cuestión en la que nos centraremos es determinar si este pacto comisorio altera o no el presupuesto específico de procedencia de la facultad resolutoria: que el incumplimiento sea resolutorio, lo que implica que el incumplimiento ha de ser de cierta entidad $^{33}$. El incumplimiento es resolutorio si las partes especifican el incumplimiento que hace procedente la resolución, con independencia de la entidad objetiva del mismo (admitiendo que hay que dar primacía a las cláusulas libremente consentidas y que tienen su justificación en la distribución de riesgos que las partes han hecho al tiempo de celebrar el contrato). Ahora bien, si las partes nada han previsto, el juez puede aplicar dos criterios, construidos a partir de diversas normas del Código Civil ${ }^{34}$ : i) un criterio objetivo, que atiende a la incidencia del incumplimiento y sus consecuencias en el propósito práctico, que las partes han incorporado expresa o tácitamente en el contrato ${ }^{35}$-si el incumplimiento priva o no sustancialmente al acreedor de lo que tenía derecho a esperar en virtud de él-; ii) un criterio subjetivo, fundado en la buena fe objetiva -artículo 1546 del CC- que se materializa en la pérdida de confianza de que el deudor cumplirá con la prestación.

Pues bien, el pacto comisorio simple solo podría tener alguna incidencia en la configuración de un incumplimiento resolutorio en la medida en que se hayan especificado los supuestos que harían procedentes la resolución. Pero al incorporarlo las partes únicamente prevén que en caso de incumplimiento pueden resolver el contrato, es decir, el pacto comisorio mismo no conlleva una especificación del incumplimiento. Si incluyera esa especificación no podría ser calificado, en consecuencia y a la luz de las disposiciones del Código Civil, como un pacto comisorio (sería uno de los pactos lícitos

${ }^{33}$ En nuestra opinión, ese es el único requisito propio que incide en la facultad resolutoria del art. 1489 CC. Los otros requisitos que tradicionalmente menciona la doctrina (la imputabilidad, y la necesidad de constituir en mora al deudor) se vinculan con la procedencia de otro remedio, el de la indemnización de perjuicios. Acerca del particular, véase Mejías Alonzo, C, El incumplimiento resolutorio en el Código Civil, LegalPublishing, Santiago, 2011, pp. 11-53.

${ }^{34}$ Principalmente, a propósito de los contratos en particular, y especialmente, en la regulación de la compraventa (arts. 1852 inciso final, 1854, 1858, 1860 y 1868 CC) y del arrendamiento (arts. 1925, 1926, 1928,1930 y 1932 CC).

${ }^{35}$ Con esta expresión nos referimos a los motivos que las partes introducen expresa o tácitamente al contrato y que aspirar obtener con su cumplimiento oportuno. Véase, por ejemplo, Capitant, H, cit. (n. 31), p. 9; De Castro y Bravo, F., El negocio jurídico, Civitas, Madrid, 2002 (reimpr.), pp. 29, 228-229; Morales Moreno, A. M., "El "propósito práctico" y la idea de negocio jurídico en Federico de Castro", en Anuario de Derecho civil, vol. 36 (4), 1983, pp. 1529-1546; y Diez-Picazo y Ponce de León, L., "El concepto de causa en el negocio jurídico", Anuario de Derecho civil, vol. 16 (1), 1963, pp. 3-32. 
que los contratantes pueden agregar en uso de su libertad contractual, configurando internamente el contrato). Entendemos, por tanto, que la inclusión del pacto comisorio simple, por su propio contenido, no tiene relevancia en la materia.

La otra cuestión que nos interesa plantear es su posible incidencia en los efectos de la resolución. Por una parte, si su inclusión permite sostener que la resolución opera sin necesidad de declaración judicial, es decir, que da lugar a un modelo de resolución automático o extrajudicial y, por otra, en el alcance de los efectos -una vez declarada o constatada- respecto de terceros.

Tradicionalmente, entre nosotros, se ha discutido si el pacto comisorio, entendido en términos amplios, opera realmente de pleno derecho de forma automática ante el incumplimiento $^{36}$. La doctrina nacional mayoritaria, asumiendo que el pacto comisorio simple no es más que la condición resolutoria expresada, concluye que requeriría de declaración judicial y esto permitiría al deudor pagar hasta antes de la citación para oír sentencia en primera instancia o de la vista de la causa, en segunda instancia, por aplicación del art. $310 \mathrm{CPC}^{37}$. La situación es distinta en el denominado pacto comisorio calificado, como lo veremos más adelante. Por nuestra parte, creemos que no hay distingos en la forma en que produce efectos el pacto comisorio simple y la facultad resolutoria del artículo 1489 del CC; concebida como una facultad que detenta el acreedor lesionado por el incumplimiento, su ejercicio necesariamente debe hacer precluir la posibilidad de que el deudor pueda enervar la acción pagando. De esta forma, lo dispuesto en el art. 310 CPC solo le habilita a oponer la excepción de pago efectivo, lo que presupone que este se haya producido con anterioridad al momento en que el acreedor haya optado por la resolución ${ }^{38}$.

Por último, detengámonos brevemente en la posible utilidad del pacto comisorio, ahora en relación con los efectos de la resolución respecto de terceros. Como es sabido, nuestra doctrina concluye que la acción reivindicatoria que conceden los arts. 1490 y 1491 CC procede solo tratándose de terceros poseedores de mala fe. Y se entiende que esa mala fe existe por la sola circunstancia de constar en el título la condición, lo que ocurre no solo en el caso de las condiciones resolutorias expresas (como sería, a estos efectos, el pacto comisorio) ${ }^{39}$, sino también tratándose de la condición "tácita” del art. 1489 CC, en la medida que existan prestaciones pendientes de pago, porque -sigue

${ }^{36}$ La discusión se ha centrado principalmente en el denominado pacto comisorio calificado, dejándose de lado el art. 1879 CC, que se considera excepcional [véase, por ejemplo, Abeliuk, R., cit. (n. 4), pp. 663664; Alessandri Rodríguez, cit. (n. 9), pp. .469-495; Pizarro Wilson, cit. (n. 12), pp. 252-254.

37 Vío, cit. (n. 32), pp. 333-335. Díez Duarte, cit. (n. 32), pp. 345-347.

${ }^{38}$ En la doctrina nacional en esta dirección Peñailillo Arévalo, cit. (n. 4), pp. 416 y ss.; Elgueta Anguita, A., Resolución de contratos y excepción de pago, Editorial Jurídica, Santiago, 1981, p. 144; Barros Bourie, E., "Finalidad y alcance de las acciones y los remedios contractuales", en Guzmán Brito, A. (coord.), Estudios de derecho civil III, LegalPublishing, Santiago, 2007, pp. 425-426; Vidal Olivares, A., "El incumplimiento resolutorio en el Código Civil", en Pizarro Wilson, C. (coord.), Estudios de derecho civil IV, LegalPublishing, Santiago, 2009, pp. 353-355. En este mismo sentido, la SCS de 15 de mayo de 2014 (291-2013) Agrícola María Inés Ltda. Con Londres Fuentes [CL/JUR/2368/2014].

${ }^{39}$ Alessandri Rodríguez, cit. (n. 9), pp. 464-465; Vío Vásquez, cit. (n. 32), p. 326; Rodríguez Grez, P., La extinción convencional de las obligaciones, Jurídica de Chile, Santiago 2006, p. 244. 
este argumento- si ello consta en el título, es posible prever que puede verificarse un incumplimiento, lo que denotaría un comportamiento poco diligente del contratante, que, a estos efectos, se asimila a "mala fe" ${ }^{40}$. Esta comprensión por parte de la doctrina determina que la introducción del pacto comisorio tampoco tiene ninguna función en relación con la aplicación de los arts. 1490 y 1491 CC $^{41}$.

\section{LA JUSTIFICACión DEL PACTO COMISORIO “CALIFICADO”}

Las partes pueden no solo estipular que el contrato se resolverá en caso de no pagarse el precio en el tiempo convenido, sino que pueden pactar que el contrato se resuelva ipso facto. En tal caso, estamos en presencia de un pacto comisorio "con cláusula de resolución ipso facto" o, como también suele denominarse, "calificado". El Código admite dicha estipulación, pero determina sus efectos: aun cuando las partes hayan pactado la resolución ipso facto, el comprador podrá, sin embargo, hacerlo subsistir, pagando el precio, lo más tarde, en las veinticuatro horas subsiguientes a la notificación judicial de la demanda (art. 1879 CC).

La doctrina suele plantear varias cuestiones relativas al pacto comisorio calificado, acerca de las que no vamos a detenernos en este trabajo. Entre esas cuestiones, por ejemplo: se destaca que no es necesario emplear ciertas palabras sacramentales ${ }^{42}$; se discute si el plazo de veinticuatro horas, al que se refiere el artículo 1879 CC es, o no, modificable por las partes (renunciable, ampliable) ${ }^{43}$; y, en general, se plantea la discusión sobre si el derecho a pagar dentro del plazo indicado existe cuando la resolución ipso facto ha sido estipulada en caso de incumplimiento de otras obligaciones, diferente de la de pagar el

${ }^{40}$ Abeliuk, cit. (n. 4), p. 547; Alessandri, A., Somarriva, M., Vodanovic, A., cit. (n. 6), pp. 302 y ss.; Claro Solar, cit. (n. 4), pp. 138, 142-143; Fueyo Laneri, F., Cumplimiento e incumplimiento de las obligaciones, $3^{a}$ ed., Editorial Jurídica, Santiago, 2004, p. 338; Peñailillo Arévalo, cit. (n. 4), pp. 453 y ss.; Vío Vásquez, cit. (n. 32), p. 391.

${ }^{41}$ Por nuestra parte, compartimos la conclusión, pero no el argumento. Creemos que esa conclusión puede justificarse de otra manera, muy diferente: sea que se trate de las denominadas condiciones expresas o de la condición tácita, puede argüirse que la mala fe debe siempre probarse, como correlato necesario de que la buena fe se presume (art. $707 \mathrm{del} \mathrm{CC).} \mathrm{Así,} \mathrm{el} \mathrm{hecho} \mathrm{de} \mathrm{que} \mathrm{en} \mathrm{el} \mathrm{título} \mathrm{respectivo,} \mathrm{inscrito} \mathrm{u} \mathrm{otorgado} \mathrm{por}$ escritura pública, conste la condición solo sería un antecedente más a considerar en la prueba de la mala fe. No debe perderse de vista que las nociones de mala fe -buena fe y culpa-diligencia no se identifican, y que la resolución, como un mecanismo de tutela del acreedor lesionado, solo procede en caso de incumplimientos resolutorios, y no frente a cualquier incumplimiento. Para este punto, véase, Boetsch Gillet, C., La buena fe contractual, Editorial Jurídica de Chile, Santiago, 2007, p. 167; y especialmente, Mejías Alonzo, C., "Una revisión crítica de la exigencia para que la resolución judicialmente decretada produzca efectos respecto de terceros”, en Estudios de Derecho civil XI, Santiago, Thompson-Reuters, 2016 [en prensa].

${ }^{42}$ En general, se entiende que no es necesario el uso de palabras sacramentales ipso facto, mientras sea clara la intención de las partes [véase, por ejemplo, Díez Duarte, cit. (n. 32), p. 347].

${ }^{43}$ De la posibilidad de renunciar al plazo de veinticuatro horas, existe discusión. A favor, se dice que la renuncia no está prohibida [Ramos Pazos, cit. (n. 4), p. 46]. En contra, se dice que en este caso la ley pasa sobre la voluntad de las partes, favoreciendo la subsistencia del contrato, de modo que el derecho concedido al comprador no se le ha otorgado en su solo interés [Alessandri; Somarriva; Vodanovic, cit. (n. 6), pp. 280281]. Igualmente, se ha discutido si ese plazo puede ampliarse [Larraín, cit. (n. 4), p. 103]. 
precio, ya sea en un contrato de compraventa o en un contrato distinto (lo que, en realidad, es parte de una cuestión más amplia: la aplicación extensiva de la regulación legal del pacto comisorio a otros supuestos de pactos de resolución por incumplimiento $)^{44}$. En este trabajo nos interesa detenernos únicamente en uno de esos aspectos: la función que puede atribuirse a la cláusula de resolución ipso facto.

Como hemos señalado, la función que pueda asignarse al pacto comisorio calificado depende, necesariamente, de la comprensión que se tenga respecto de cómo opera la facultad resolutoria por incumplimiento exart. 1489 CC. En nuestra opinión, son dos los posibles modelos teóricos de funcionamiento de esa resolución: uno, el generalmente admitido o "tradicional"; y otro que podríamos denominar "moderno". En lo que sigue, describiremos las premisas pertinentes en las que se sostienen ambos modelos, y analizaremos cuál es la función específica que, en cada uno de esos estos, puede atribuirse al pacto comisorio calificado.

\section{Justificación del pacto comisorio calificado en el modelo tradicional de resolución por incumplimiento}

i. Explicación del modelo teórico tradicional de resolución por incumplimiento exart. 1489 CC

El modelo teórico tradicional de resolución previsto en el artículo 1489 del CC, asumido por nuestra doctrina, descansa en la concepción de una condición resolutoria

\footnotetext{
${ }^{44}$ Conviene tener presente que, pese a que el pacto comisorio está tratado al interior de la regulación de la compraventa, y en relación con una específica obligación del contrato, no parece que exista discusión en torno a que es perfectamente posible introducir pactos de resolución por el incumplimiento de otras obligaciones, sea en el contrato de compraventa, sea en otros contratos diversos. Los tribunales también admiten estos pactos, reproduciendo los argumentos doctrinales [véase, por ejemplo, la SCA de Antofagasta, de 7 de mayo de 2011 (184/2011) ICS Valle de la Luna Limitada en contra de I. Municipalidad de Calama, Id. vLex: VLEX-304640478]. El problema a dilucidar es si la regulación legal del pacto comisorio debe aplicarse extensivamente a esos pactos comisorios atípicos, y específicamente, si les resulta aplicable lo dispuesto en el art. 1879 CC. Referente al particular puede verse, por ejemplo, Fernández Stevenson, J., "Pacto comisorio calificado en contratos diversos de la compraventa", Revista de Derecho de la Universidad Católica del Norte, v. 11, n. 1, 2004, pp. 183-189, y López Díaz, C., El pacto comisorio en el contrato de arrendamiento, Editorial Metropolitana, Santiago, 2015, especialmente, p. 71 y ss. En los tribunales, se ha discutido este punto, generalmente, tratándose de pactos comisorios calificados en contratos de arrendamientos, aunque la cuestión se ha planteado también en relación con otros contratos [por ejemplo, la SCA de Antofagasta, de 20 de junio de 2011 (215-2011) Contratista Juan Fuentes Castillo E.I.R.L con Corporación Municipal del Desarrollo Regional de Antofagasta (CL7JUR/10179/2011), en relación con un contrato de prestación de servicios]. El estudio de la jurisprudencia arroja que, en general, los tribunales entienden que la regulación legal del pacto comisorio debe aplicarse restringidamente, y, en consecuencia, que lo dispuesto en el art. 1879 CC no es aplicable a otros pactos de resolución, de modo que, en ellos, la resolución se produce ipso facto por el incumplimiento, asimilándose el pacto comisorio a la condición resolutoria ordinaria; si bien suele exigirse que el acreedor manifieste su voluntad en el sentido de que el contrato se resuelva (de modo que opera con la interposición de la demanda o la notificación a la arrendataria). Ello, sin perjuicio de admitir que, en ciertos casos, esa resolución no operaría ipso facto, como ocurre, por ejemplo, tratándose del contrato de arrendamiento de predios urbanos, debido a lo dispuesto en el art. 19 de la Ley 18.101.
} 
tácita. Ha incidido, al momento de precisar sus requisitos y efectos, la ubicación de su regulación, a propósito de las obligaciones condicionales y el propio tenor del referido artículo. De allí entonces que se sostenga que sus requisitos de procedencia son: un incumplimiento imputable al deudor, su mora, que el acreedor haya cumplido con su obligación o se encuentre llano a hacerlo y la entidad del incumplimiento ${ }^{45}$.

En este modelo nos interesa poner de relieve dos aspectos vinculados a la producción de efectos de la resolución. El primero se vincula, en concreto, con el momento en que opera la resolución. Al acreedor se le otorga un derecho a pedir la resolución; y, por tanto, debe ser declarada por el juez. De esto resulta que sus efectos se producen siempre con la sentencia judicial que la declara; más precisamente, una vez que dicha sentencia quede firme o ejecutoriada, conservando el contrato su vigor hasta ese momento. En este modelo, al deudor que es sancionado por su incumplimiento le asiste siempre la posibilidad de liberarse pagando, en definitiva prima su derecho al pago por sobre la resolución demandada por el acreedor ${ }^{46}$. Esto es plenamente coherente con la visión de incumplimiento que esta doctrina acoge: un acto injusto, una infracción a los deberes de conducta que el contrato le impone y, que por tanto, puede ser subsanado ${ }^{47}$.

El segundo aspecto se relaciona con la oportunidad en que se admite que el deudor pueda pagar y, por esta razón, enervar la acción deducida. Esta oportunidad la fijaría el art. 310 CPC, norma a la que se le da una particular lectura fundada en la interpretación que se hace del art. 1489 CC, y se afirma que el deudor-demandado- puede pagar en cualquier momento hasta antes de la citación para oír sentencia, en primera instancia y, en segunda instancia, hasta antes de la vista de la causa. Precisamente como le asiste el derecho de pagar, que es consecuencia de su necesidad jurídica de dar cumplimiento a su prestación, se le permite incluso acudir a la modalidad del pago por consignación, si el acreedor no quiere recibir el pago ${ }^{48}$. Se advierte que es un modelo que privilegia el interés del deudor por sobre el interés del acreedor; la procedencia real de la resolución y la vigencia del contrato quedan entregadas a la conducta que despliega el deudor, incluso después de haber incumplido.

\footnotetext{
45 Por todos Claro Solar, L., cit. (n. 4), pp. 178 y ss. Abeliuk, cit. (n. 4), pp. 647-659. Alessandri Rodríguez, cit. (n. 9), pp. 347 y ss.

${ }^{46}$ Claro Solar, L., cit. (n. 4), pp. 176 y ss.; y especialmente, p. 187; y Abeliuk, cit. (n. 4), pp. 662663. En este sentido, SCS de 14 de enero de 2010 (5431-2008), Ivanyi Gaspar, Andrea contra Emben Blumer, Juan Carlos, (CL/JUR/792/2010); SCS de 11 de abril de 2011 (7036-2009) Agreda Pobl Ignacio c. Sande S.A. (CL/JUR/2990/2011); SCS de 11 de abril de 2011 (7957-2009), Jaime Venegas Castro con Inmobiliaria Río Trancura S.A (CL/JUR/3095/2011).

47 Acerca de la visión tradicional y moderna de incumplimiento, véase Mejías Alonzo, C., "El incumplimiento contractual y sus modalidades”, en Guzmán Brito, A., Estudios de Derecho Civil III, Editorial LegalPublishing, Santiago, 2008, pp. 459-478.

${ }^{48}$ Art. $310 \mathrm{CPC}$ inc. $1^{\circ}$ : No obstante lo dispuesto en el artículo anterior, las excepciones de prescripción, cosa juzgada, transacción y pago efectivo de la deuda, cuando esta se funde en un antecedente escrito, podrán oponerse en cualquier estado de la causa; pero no se admitirán si no se alegan por escrito antes de la citación para sentencia en primera instancia, o de la vista de la causa en segunda. Reiteramos la opinión que sostuvimos a propósito del pacto comisorio simple: una vez ejercitada la facultad resolutoria, el deudor no podría enervarla pagando, véase apartado II.2.ii. En este sentido, Claro Solar, L., cit. (n. 4), pp. 176 y ss.; Abeliuk, cit. (n. 4), pp. 662-663.
} 


\section{ii. Justificación funcional del pacto comisorio calificado en este modelo}

En este modelo teórico de resolución, la introducción del pacto comisorio calificado es útil precisamente porque modifica la oportunidad en que el deudor puede enervar la acción, mas no la forma en que opera la resolución exart. 1489 CC.

Con relación a la oportunidad en que opera la resolución del art.1879 CC -y que puede entenderse incide en la posibilidad de pagar del deudor-, nuestra doctrina ha planteado tres alternativas. Para algunos, la resolución operaría por incumplimiento del pago del precio. Para otros, una vez que han transcurrido las 24 horas siguientes a la notificación judicial de la demanda porque el deudor ya no podrá enervar la resolución. Finalmente, se ha sostenido que la resolución opera solo por sentencia judicial, pero se reconoce que en ningún caso podría el comprador pagar más allá del referido plazo $^{49}$. En cualquier caso -y esto es lo que nos interesa destacar-el límite máximo que la doctrina ha previsto es el legal: 24 horas siguientes a la notificación judicial de la demanda, plazo bastante más breve que el que maneja la doctrina tradicional en materia de resolución exart.1489.

Nosotros entendemos que la introducción de la cláusula de resolución ipso facto no tendría que leerse como una voluntad de las partes para dar por resuelto el contrato por el solo hecho del incumplimiento de la obligación de pagar el precio; ni que pierde el vendedor el derecho a pedir el cumplimiento (art. 1878 CC, en relación con el art. 1873 CC). El efecto del pacto comisorio calificado es $-\mathrm{y}$ esto es lo que hay que entender que las partes han querido- restringir la posibilidad del deudor de enervar la acción pagando en cualquier momento del juicio: solo puede hacerlo dentro de las veinticuatro horas siguientes a la notificación judicial de la demanda. Por ello se sostiene que el pacto beneficiaría al vendedor, cuya situación mejoraría considerablemente al tener más probabilidades de no ver fracasada su demanda y obtener la resolución, ya que sin el pacto el beneficiado es el comprador que tiene más plazo para pagar ${ }^{50}$. No debe perderse de vista que el incumplimiento que hace operar el pacto es el de la obligación de pagar el precio, de manera que permitirle al deudor pagar en este reducido plazo, resguarda de todas formas el interés contractual del acreedor.

La justificación de esa funcionalidad puede explicarse acudiendo a la teoría general de las obligaciones. El pacto comisorio puede ser entendido como una condición resolutoria ordinaria y expresa, con la particularidad (si es que puede decirse que lo sea) de estar establecida en beneficio exclusivo del acreedor, quien, por tanto, puede renunciar a ella, de conformidad al artículo 12 del CC (por ejemplo, y simplemente, no pidiendo que se constate la verificación del hecho en que la condición consiste). De esta forma el acreedor, no obstante haberse cumplido la condición, puede, igualmente, exigir el

${ }^{49}$ Vío Vásquez, cit. (n. 32), pp. 335-339. Abeliuk, cit. (n. 4), pp. 664-666. Claro Solar, cit. (n. 26), pp. 198-199. Alessandri Rodríguez, cit. (n. 9), pp. 40-481.

${ }^{50}$ Alessandri Rodríguez, cit. (n. 9), p. 493; y también, Abeliuk, cit. (n. 4), pp. 664-666; Larraín, H, cit. (n. 4), p. 102; Meza Barros, R., Manual de Derecho civil, Editorial Jurídica, Santiago, 2007, pp. 45-46. 
cumplimiento. Mientras no exista manifestación por parte del acreedor de su voluntad de resolver, el contrato existe, y puede, por tanto, ser cumplido.

Otra explicación puede ensayarse desde el prisma de los derechos o medios de tutela del acreedor (los “remedios") frente al incumplimiento contractual. La funcionalidad del pacto comisorio calificado se justificaría sobre la base de admitir la siguiente premisa: las partes, en ejercicio de su libertad contractual, pueden perfectamente modificar la variedad de medios de tutela o remedios que el ordenamiento jurídico les ofrece, para la caso de incumplimiento de la otra parte, ampliándolo o restringiéndolo. El alcance de esa afirmación de entrada es algo que puede discutirse, en particular, en lo que respecta a la renuncia anticipada al cumplimiento específico. Pero, asumiendo esa premisa como principio, es posible decir que al incorporar un pacto comisorio calificado lo que las partes hacen es restringir la oportunidad que tiene el deudor para pagar; la razón de un pacto de esta naturaleza descansa, en último término, en la distribución de riesgos que los contratantes realizan a través del contrato.

\section{Justificación del pacto comisorio calificado en un modelo moderno de resolución por incumplimiento}

i. Explicación del modelo moderno de resolución por incumplimiento exart. 1489 CC

En una visión más moderna, la resolución por incumplimiento exart. 1489 CC es una facultad más de que dispone el acreedor en caso de incumplimiento resolutorio y no una condición, de manera que su estudio se inserta en el tópico del incumplimiento y no en las obligaciones condicionales.

La doctrina, que hemos calificado de moderna, ha centrado sus esfuerzos en ofrecer una relectura de las normas del incumplimiento contractual y sus efectos que sea coherente con las actuales condiciones del tráfico, que claramente difieren del modelo que tuvo a la vista el codificador decimonónico ${ }^{51}$. En relación con los requisitos de la resolución, se concluye que solo la gravedad determina su procedencia, descartándose los demás que ya hemos mencionados. Se trata de conciliar el interés del acreedor con la fuerza obligatoria del contrato y la conservación del negocio jurídico. De esta forma la resolución exartículo 1489 se nos presenta como una facultad que le permite al acreedor desvincularse del contrato con la finalidad de acudir al mercado en busca de la forma más adecuada para satisfacer su interés lesionado ${ }^{52}$.

${ }^{51}$ En la materia puede consultarse Vidal, A., "El incumplimiento de obligaciones con objeto fungible y los remedios del acreedor afectado. Un intento de relectura de las disposiciones del Código Civil acerca del incumplimiento, en Guzmán Brito, A. (coord.), El Código Civil de Chile (1855-2005). Morales Moreno, A., Modernización del Derecho de obligaciones, Editorial Civitas, Madrid, 2006.

52 Tratándose de la resolución puede consultarse Peñailillo Arévalo, cit. (n. 4), pp. 392-419. Mejías, C., cit. (39), pp. 36-53, 206 y ss. 
Por lo anterior, el momento en que se produce la resolución está vinculado al ejercicio de la facultad (temporalmente: la presentación de la demanda o su notificación legal), lo que a su vez importa un límite que excluye la posibilidad del deudor de cumplir. En este contexto, la tarea del juez se circunscribe a constatar si el incumplimiento es o no resolutorio; si lo es, el contrato se entiende resuelto desde el momento en que el acreedor ha ejercido esta facultad; si no lo es, el contrato seguirá vigente y el ejercicio de esta facultad será considerado como un incumplimiento contractual por parte de ese acreedor, lo que abrirá paso a los remedios frente al incumplimiento.

\section{ii. Justificación funcional del pacto comisorio calificado en este modelo}

En este modelo introducir un pacto comisorio parecería inútil. Sin embargo, como es de lógica suponer que su introducción se justifique porque modifica, en algún sentido, la forma de operar la resolución exartículo 1489 CC, exploraremos alternativas que vayan en esa dirección.

Una posibilidad es concluir, atendido el tenor literal del Código Civil, que el pacto tiene por finalidad permitir al deudor, en el plazo de veinticuatro horas, pagar y enervar la resolución, derecho del que carece frente al ejercicio de la facultad resolutoria exart. 1489 CC. Pero ello implica admitir que la introducción de una cláusula ipso facto tiene un efecto contrario al que se desprende de su propio tenor: precisamente, la finalidad perseguida por las partes sería, conociendo ellas el efecto atribuido por la ley a esa cláusula, que la resolución por incumplimiento no operará ipso facto ${ }^{53}$.

Otra posible función, que parte de la doctrina reciente y nuestra jurisprudencia le han dado al pacto comisorio calificado, es de una verdadera condición resolutoria ordinaria, pero ya no entendida en beneficio exclusivo del acreedor, sino que entendida como una condición que está establecida en interés de ambas partes contratantes. Así, la existencia de un pacto comisorio calificado determinaría, sin más, la resolución del contrato en caso de incumplimiento, si bien, por expresa disposición de la Ley, la resolución se produciría una vez transcurridas las veinticuatro horas siguientes a la notificación de la demanda (demanda en la que no pide, por tanto, que se declare la resolución del contrato, sino otra pretensión fundada en el contrato resuelto, por ejemplo, la restitución de la cosa entregada) ${ }^{54}$. De esta manera no necesitaría el acreedor solicitar al juez que declare la resolución, sin perjuicio de que pueda constatar su ocurrencia.

${ }^{53}$ López Santa María, J., Los contratos, Abeledo Perrot, Santiago, 2010, 5 a edición, pp. 236 y 503.

${ }^{54}$ Rodríguez Grez, cit. (n. 45), pp. 245-246. En el mismo sentido, Pizarro Wilson, cit. (n. 12), p. 250.

En los tribunales, y a propósito del pacto comisorio simple, por ejemplo, la SCA de Antofagasta, de 20 de junio de 2011 (215-2011) Contratista Juan Fuentes Castillo E.I.R.L. con Corporación Municipal de Desarrollo Regional de Antofagasta (CL/JUR/10179/2011). Y lo han sostenido expresamente en relación con los pactos de resolución en otros contratos, en las que no opera el plazo del art. 1879 CC. Por ejemplo, en materia de arrendamiento, la SCS de 8 de agosto 1996 (33888) Marcelo Llanos con Julio Braunfeld (CL/JUR/621/1996); la SCS de 8 de marzo de 2004 (3279-2003) Carlos Alberto Acevedo Crisóstomo con Sociedad Combustibles Marítimos Sociedad Anónima (CL/JUR/2692/2004); la SCS de 9 de abril de 2007 (5869-2005) Patricia Ramona Gavilán Avello con Genoveva Toro Toro; Humberto Bernasconi Apolonio (CL/JUR/5818/2007); la SCA de Concepción, de 
Ahora bien, hay que tener presente que la mayoría de la doctrina y de la jurisprudencia nacional considera que no es posible asimilar el pacto comisorio calificado a una condición resolutoria ordinaria. Si así fuera -se dice- el contratante incumplidor decidiría la vida del contrato, lo que resulta inadmisible ${ }^{55}$. El argumento se refuerza con la cita al texto del art. 1878 CC, que establece, que por el pacto comisorio no se priva al vendedor de la elección de acciones que le concede el artículo 1873 CC. El mentado del art. 1873 CC señala que si el comprador estuviere en mora de pagar el precio en el lugar y tiempo dichos, el vendedor tendrá derecho para exigir el precio o la resolución de la venta, con resarcimiento de perjuicios. Pero esos argumentos de la doctrina mayoritaria no parecen determinantes. Descontando el argumento de texto del art. 1878 CC (que, en realidad, no representa un escollo insoslayable, pues bien puede entenderse que, por su ubicación, dicho artículo está referido al pacto comisorio simple y no al calificado), persiste la pregunta acerca de si puede admitirse que la resolución opere precisamente como las partes quieren que opere: ipso facto y en beneficio de ambas. Es una idea que, creemos, vale la pena explorar, considerando la atención que, en el último tiempo, viene dando la doctrina nacional al tema del incumplimiento contractual y los remedios del acreedor.

El soporte teórico de esa función del pacto comisorio calificado -resolución ipso facto por el solo hecho del incumplimiento- se vincula a una noción económica-realista del contrato, concebido como un instrumento de distribución de riesgos, que admite que las partes pueden perfectamente prever la situación de incumplimiento contractual y determinar libremente sus consecuencias. Desde este punto de vista, las acciones y derechos que concede la ley al contratante no incumplidor para el caso del incumplimiento tienen naturaleza dispositiva, de modo que su contenido puede ser modificado por las partes. Así, el derecho a exigir el cumplimiento específico, una vez producido el incumplimiento, puede ser considerado un derecho renunciable, de conformidad al artículo 12 CC, y sin que nada obste su renuncia anticipada al momento de contratar, que es precisamente el efecto que tendría, según este punto de vista, introducir un pacto comisorio calificado ${ }^{56}$.

Aunque la doctrina no ha desarrollado mayormente esta posición, creemos que es posible esgrimir otros buenos argumentos en apoyo de ella. Por una parte, porque el

20 de octubre (345-2014) Jarufe Robles y Cía. Ltda. con Sandoval Jara Felicia Mireya (VLex-579480630); o en relación con el incumplimiento de una dación en pago estipulada en una compraventa, la SCS de 26 de junio de 2001 (4148-1999), Cooperativa de Viviendas y Servicios Habitacionales Rafael Sotomayor Limitada; con Inversiones y Rentas San Pablo S. A. (CL/JUR/1529/2001).

55 Vío Vásquez, cit. (n. 32), p. 335. Claro Solar, cit. (n. 26), pp. 198-199. Abeliuk, cit. (n. 4), pp. 665-666.

${ }^{56}$ En este sentido, por ejemplo, Pizarro Wilson, aunque vertiendo su opinión a propósito del pacto comisorio atípico en el contrato de arrendamiento, sostiene que "[a]l establecerse un pacto comisorio calificado las partes renuncian al cumplimiento específico - ejecución en naturaleza-y optan por un remedio contractual que opera en forma automática con la mera inejecución" [Pizarro Wilson, C., "Pacto comisorio calificado. Necesidad de un acto recepticio por el acreedor (Corte Suprema, 21 de enero de 2013, rol 5504-2011)", Revista Chilena de Derecho Privado, n. 21, 2013, p. 341]. En este mismo sentido, Botteselle, A, "El pacto comisorio como manifestación de la facultad resolutoria”, en Revista chilena de Derecho privado, v. 7, 2011 , p. 86. 
contrato no requiere estructurarse en torno al derecho al cumplimiento específico; esa es la aproximación del Common law, y no por ello se pone en tela de juicio la justificación del contrato como institución ${ }^{57}$. Por otra parte, hay que considerar que la legislación procesal impone diversos límites al derecho del acreedor a la ejecución in natura, poniendo en tela de juicio su pretendido carácter de remedio preeminente, que es precisamente lo que impediría su renuncia anticipada ${ }^{58}$. Finalmente, no debe perderse de vista que la renuncia al cumplimiento específico no implica una renuncia al interés en el cumplimiento, pues el cumplimiento específico es solo a una vía concreta de obtener ese beneficio del contrato; el acreedor puede solicitar un cumplimiento por equivalente ${ }^{59}$.

Pese a todo lo dicho, creemos que no es admisible otorgar esa función al pacto comisorio sin desnaturalizar la estructura misma de las obligaciones que las partes han asumido en el contrato; en último término, compartimos con la posición mayoritaria de la doctrina, pero por razones distintas de las generalmente esgrimidas. No se trata de dejar "la vida del contrato" entregada a la parte incumplidora. Sí entendemos que el pacto comisorio opera como una condición resolutoria ordinaria, establecida en beneficio de ambos contratantes, ello implica que el contratante no incumplidor ha renunciado, al momento de celebrar el contrato, al derecho a exigir el cumplimiento. Mirada esta situación en un modelo contractual que pone el acento en el deber de prestación del deudor, la idea de renunciar al cumplimiento específico de manera anticipada es difícil de aceptar, porque implica privar de contenido a ese deber de prestación. La posibilidad de exigir el cumplimiento de la prestación es un elemento estructural de la noción de derecho personal y de su correlato, la obligación. Si no existe derecho a exigir el cumplimiento de la prestación, no existe propiamente una obligación. Lo anterior se refleja con claridad en el contrato de compraventa, cuyos elementos esenciales particulares son la entrega de la cosa y el pago del precio. Si no existe la obligación de pagar el precio, porque no ha surgido su correlato necesario (el derecho para exigir su entrega), el contrato ha degenerado en uno distinto (art. 1444 CC). No podría calificarse jurídicamente de compraventa.

En definitiva partimos de esta premisa: toda obligación presupone un vínculo jurídico, siendo inherente a él la posibilidad del acreedor de exigir el cumplimiento de la prestación. Su fundamento radica en el contrato válidamente celebrado, en particular, en el derecho que aquel crea para el acreedor. Su renuncia, al momento de contratar, implica que ese derecho no nace, $y$, al mismo tiempo y necesariamente, que no exista la

${ }^{57}$ A propósito del particular, véase, por ejemplo, Severin Fuster, G., "Sobre el carácter secundario y discrecional del remedio del cumplimiento específico en el Common Law. Perspectiva histórica y aproximación actual”, Revista Chilena de Derecho, v. 43, n. 2, abril de 2016, pp. 7-37.

${ }^{58}$ En general, de la estrecha relación entre la afirmación de un derecho (sustantivo) al cumplimiento específico y los límites procesales de la ejecución in natura, véase Pérez Ragone, Á., “¿Nemo praecisi coegit ad factum? Reinterpretación desde la tutela ejecutiva efectiva de las obligaciones no dinerarias”, Revista de Derecho de la Pontificia Universidad Católica de Valparaíso, n. 43, $2^{\circ}$ semestre, 2014, pp. 355-383.

${ }^{59}$ Véase López Díaz, P., "La indemnización compensatoria por incumplimiento de los contratos bilaterales como remedio autónomo en el Derecho Civil chileno”, Revista Chilena de Derecho Privado, n. 15, 2010, pp. 65-113. 
obligación correlativa. No se debe olvidar que es en este vínculo jurídico donde nuestra doctrina tradicionalmente hace descansar el derecho de garantía general de los acreedores, que se activa frente el incumplimiento de esa obligación, abriendo paso a los remedios del acreedor ${ }^{60}$. Si no existe obligación, no podemos hablar de incumplimiento, que es presupuesto fundamental para que pueda operar cualquier mecanismo de tutela.

Luego de haber explorado las posibles funciones atribuibles al pacto comisorio calificado y habiéndose negado la posibilidad de que opere como una condición resolutoria ordinaria, solo es posible concluir que su utilidad es reducida o inexistente, en un modelo que concibe a la facultad resolutoria que concede el art. 1489 CC como un remedio más del acreedor frente al incumplimiento. Su introducción solo podría implicar que las partes desean que, por expresa disposición del legislador, se prescinda del tenor literal empleado (ipso facto), otorgándose al deudor un breve plazo para que cumpla y, por esta razón, de enervar la acción resolutoria, posibilidad que no tendría en el régimen de resolución exart. 1489 CC. Sin embargo, admitimos que en la práctica la utilidad del pacto comisorio es indudable porque si bien la doctrina nacional tiende actualmente a concebir a la resolución de forma moderna, no acontece lo mismo en los pronunciamientos de nuestros tribunales, de manera que este pacto constituye una útil herramienta para que el acreedor resguarde sus derechos.

\section{BIBLIOGRAFÍA}

Abeliuk Manasevich, R., Las obligaciones. Tomo I, $6^{a}$ ed., LegalPublishing (Thompson Reuters), Santiago, 2014.

Alessandri Rodríguez, A., De la compraventa y de la promesa de venta, Jurídica de Chile, Santiago, 2011 (T. II. V. 1).

Alessandri Rodríguez, A., Derecho civil. Primera parte. Teoría de las obligaciones, Impr. CisnerosSan Francisco, Santiago, 1930.

Alessandri, A.; Somarriva, M., Vodanovic, A., Tratado de las obligaciones. Volumen de las obligaciones en general y sus diversas clases, $2^{\mathrm{a}}$ ed., Jurídica de Chile, Santiago, 2001.

Arangio-Ruiz, V., La compravendita in diritto romano, t. II. Jovene, Napoles, 1954.

BArros Bourie, E., "Finalidad y alcance de las acciones y los remedios contractuales", en Guzmán Brito, A. (coord.), Estudios de derecho civil III, LegalPublishing, Santiago, 2007.

Bello, A., Código Civil (1853) (Proyecto de), en Consejo de instrucción pública, Obras completas de don Andrés Bello, V. XII: Proyecto de Código Civil de 1853, Imprenta de Pedro Ramírez, Santiago, 1888.

Boetsch Gillet, C., La buena fe contractual, Editorial Jurídica de Chile, Santiago, 2007.

Botteselle, A., "El pacto comisorio como manifestación de la facultad resolutoria", en Revista Chilena de Derecho Privado, v. 17, 2011, pp. 71-103.

Boyer, G., Recherches historiques sur la résoltuion des contrats, Les presses universitaires de France, Paris, 1924. 
Cassin, R. De l'exception tirée de l'inexécution dans les rapports synallagmatiques: exception non adimpleti contractus, Paris, Librairie de la Société du Recueil Sirey, 1914.

Capitant, H., De la causa de las obligaciones, Editorial Góngora, Madrid, 1930.

Claro Solar, L., Explicaciones de Derecho civil chileno y comparado, T. 10: De las obligaciones, Jurídica de Chile, Santiago, 1988 (v. 5, reimpresión).

Claro Solar, L., "Ligeras observaciones sobre la condición resolutoria y el pacto comisorio (notas para alegar)", en Tavolari Oliveros, R., Doctrinas esenciales. Derecho civil. Contratos. Tomo 1, Santiago, Jurídica de Chile, 2010.

De Castro y Bravo, F., El negocio jurídico, Civitas, Madrid, 2002 (reimpr.).

Delvincourt, C.E., Cours de Code civil, 9a ed., P.J. de Mat, Bruxelles, 1925.

DíEz Duarte, R., La compraventa, $2^{\mathrm{a}}$ ed,. El Jurista, Santiago, 2009.

Diez-Picazo y Ponce de León, L., "El concepto de causa en el negocio jurídico”, Anuario de Derecho civil, vol. 16 (1), 1963, pp. 3-32.

Domat, Les lois civiles dans leur ordre natural, París, la Veuve Cavelier, 1771.

Domínguez Águila, R., La prescripción extintiva, Editorial Jurídica de Chile, Santiago, 2004.

Elgueta Anguita, A., Resolución de contratos y excepción de pago, Editorial Jurídica, Santiago, 1981.

FERnÁndez Stevenson, J., "Pacto comisorio calificado en contratos diversos de la compraventa", Revista de Derecho de la Universidad Católica del Norte, v. 11, n. 1, 2004, pp. 183-189.

Fueyo Laneri, F., Cumplimiento e incumplimiento de las obligaciones, $3^{\mathrm{a}}$ ed., Editorial Jurídica, Santiago, 2004.

García del Corral, I., Cuerpo de Derecho Civil Romano, Jaime Molinas, Barcelona, 1889.

Gómez de la Serna, P; Montalban, J. M., Elementos del derecho civil y penal de España, t. 2, Establecimiento Tipográfico Calle del Sordo, Madrid, 1842.

GuZMÁn Brito, Derecho privado romano, T. II, Jurídica de Chile, Santiago, 2010.

Jörs, P.; Kunkel, W., Derecho privado romano, trad. de Prieto Castro, L, Editorial Labor, Barcelona, 1937.

Larraín Ríos, H., Teoría general de las obligaciones, LexisNexis, Santiago, 2003.

Levy, J. Ph.; Castaldo, A., Histoire du droit civil, Paris, Dalloz, 2002.

López Díaz, C., El pacto comisorio en el contrato de arrendamiento, Editorial Metropolitana, Santiago, 2015.

López Santa María J., Los contratos, Abeledo Perrot, Santiago, 2010, 5 a edición.

Mejías Alonzo, C, El incumplimiento resolutorio en el Código Civil, LegalPublishing, Santiago, 2011.

Mejías Alonzo, C, "Una revisión crítica de la exigencia para que la resolución judicialmente decretada produzca efectos respecto de terceros", en Estudios de Derecho civil XI, Santiago, Thompson-Reuters, 2016 [en prensa].

Mejías Alonzo, C, "El incumplimiento contractual y sus modalidades”, en Guzmán Brito, A., Estudios de Derecho Civil III, Editorial LegalPublishing, Santiago, 2008, pp. 459-478.

Meza Barros, R., Manual de Derecho civil, Editorial Jurídica, Santiago, 2007, pp. 45-46.

Morales Moreno, A. M., “El 'propósito práctico' y la idea de negocio jurídico en Federico de Castro", Anuario de Derecho civil, vol. 36 (4), 1983, pp. 1529-1546.

Morales Moreno, A. M., Antonio Manuel, Modernización del Derecho de obligaciones (Madrid, 2006).

Peñailillo Arévalo, D., Obligaciones. Teoría general y clasificaciones. La resolución por incumplimiento, Jurídica de Chile, Santiago, 2006.

PÉrez Ragone, Á., “ ¿Nemo praecisi coegit ad factum? Reinterpretación desde la tutela ejecutiva efectiva de las obligaciones no dinerarias", Revista de Derecho de la Pontificia Universidad Católica de Valparaíso, n. 43, $2^{\circ}$ semestre, 2014, pp. 355-383.

Pizarro Wilson, C., "Las cláusulas resolutorias en el Derecho civil chileno”, en De la Maza, I. (edit.) Cuadernos de Análisis jurídico. Colección Derecho Privado III. Temas de contratos., Universidad Diego Portales, Santiago, 2006. 
Pizarro Wilson, C., "Pacto comisorio calificado. Necesidad de un acto recepticio por el acreedor (Corte Suprema, 21 de enero de 2013, rol 5504-2011)”, Revista Chilena de Derecho Privado, número 21, 2013, pp. 339-342.

Pothier, R. J., Ouvres de R.-J. Pothier, contenant les traités du droit français. T. 1, H. Tarlier, Bruxelles, 1831.

Ramos Pazos, R., Manual de Derecho civil. De las obligaciones, 10ª. ed., Jurídica de Chile, Santiago, 2007.

Rodríguez Grez, P., La extinción convencional de las obligaciones, Jurídica de Chile, Santiago 2006.

SEverin Fuster, G., "Sobre el carácter secundario y discrecional del remedio del cumplimiento específico en el Common Law. Perspectiva histórica y aproximación actual”, Revista Chilena de Derecho, v. 43, n. 2, abril de 2016, pp. 7-37.

Vial del Río, V., Manual de las Obligaciones en el Código Civil chileno, $2^{\mathrm{a}}$ ed., Editorial Biblioteca Americana, Santiago, 2007.

Vidal Olivares, A., "El incumplimiento resolutorio en el Código Civil", en Pizarro Wilson, C. (coord.), Estudios de derecho civil IV, LegalPublishing, Santiago, 2009, pp. 353-355.

VIDAL Olivares, A., "El incumplimiento de obligaciones con objeto fungible y los remedios del acreedor afectado. Un intento de relectura de las disposiciones del Código Civil sobre incumplimiento", en Guzmán Brito, A. (coord.), El Código Civil de Chile (1855-2005).

Vío Vásquez, E., Las obligaciones condicionales, Escuela de tipografía salesiana, Concepción, 1945.

Wegmann Stockebrand, A., "Algunas consideraciones sobre la prohibición del pacto comisorio y el pacto marciano”, Revista chilena de Derecho privado, v.13, 2009, p. 95-122.

Zimmerman, R., The Law of Obligations. Roman foundations of the civilian tradition, 1. ${ }^{a}$ ed, Juta and Co., Cape Town, 1990 (reimpresión 1992). 
